(2)

\title{
Clinical and biochemical characteristics and bone mineral density of homozygous, compound heterozygous and heterozygous carriers of three novel IGFALS mutations
}

\author{
Emregül Işık', Belma Haliloglu², Jaap van Doorn³ ${ }^{3}$ Hüseyin Demirbilek, \\ Sitha A Scheltinga5, Monique Losekoot ${ }^{5}$ and Jan M Wit ${ }^{6}$ \\ ${ }^{1}$ Department of Pediatric Endocrinology, Gaziantep Children's Hospital, Gaziantep, Turkey, ${ }^{2}$ Department \\ of Pediatric Endocrinology, Yeditepe University School of Medicine, İstanbul, Turkey, ${ }^{3}$ Department of \\ Genetics, University Medical Center Utrecht, The Netherlands, ${ }^{4}$ Department of Pediatric Endocrinology, \\ Hacettepe University Faculty of Medicine, Ankara, Turkey, Departments of ${ }^{5} \mathrm{Clinical}$ Genetics and \\ ${ }^{6}$ Pediatrics, Leiden University Medical Center, Leiden, The Netherlands
}

\author{
Correspondence \\ should be addressed \\ to $E$ Işık \\ Email \\ dremregul@gmail.com
}

\begin{abstract}
Objective: Acid-labile subunit (ALS) deficiency (ACLSD), caused by homozygous or compound heterozygous IGFALS mutations, is associated with moderate short stature, delayed puberty, low serum IGF-I and ALS and extremely low serum IGFBP-3. Its effect on birth weight, head circumference, bone mineral density (BMD), serum IGF-II and IGFBP-2 is uncertain, as well as the phenotype of heterozygous carriers of IGFALS mutations (partial ACLSD).

Design: From all available members of five Turkish families, carrying three mutations in exon 2 of IGFALS (c.1462G > A, p.Asp488Asn (families A, B, E); c.251A > G, p.Asn84Ser (families C and E) and c.1477del, p.Arg493fs (family D)), clinical, laboratory and BMD data were collected.

Methods: Auxological and biochemical findings were expressed as SDS for age and gender. Ternary complex formation in serum was investigated by size-exclusion chromatography. BMD using DXA bone densitometry was adjusted for height and age (Ha-BMD z-score).

Results: In ACLSD $(n=24)$, mean \pm S.D. height SDS $(-2.7 \pm 1.2)$, head circumference SDS $(-2.3 \pm 0.5)$ and body mass index (BMI) $(-0.6 \pm 1.0$ SDS) were lower than those in partial ACLSD $(n=26, P \leq 0.01)$ and birth weight SDS ( $n=7)$ tended to be lower $(-2.2 \pm 1.1$ vs $-0.6 \pm 0.3$ in partial ACLSD $(P=0.07)$ ). Serum IGF-I was $-3.7 \pm 1.4$ vs $-1.0 \pm 1.0$, IGF-II: $-5.6 \pm 0.7$ vs $-1.3 \pm 0.7$, ALS: $<-4.4 \pm 1.2$ vs $-2.1 \pm 0.9$ and IGFBP-3: $-9.0 \pm 1.9$ vs $-1.6 \pm 0.8$ SDS respectively $(P<0.001)$. Ha-BMD $z-S c o r e$ was similar and normal in both groups.

Conclusions: To the known phenotype of ACLSD (i.e. short stature, reduced serum levels of IGF-I and ALS, extremely Iow serum IGFBP-3 and disturbed ternary complex formation), we add reduced birth weight, head circumference and serum IGF-II.
\end{abstract}

\section{Introduction}

Insulin-like growth factors (IGFs) exert a broad range of biological actions including mitogenic and anti-apoptotic effects, which necessitates adequate regulation to ensure normal growth and development. The availability of
European Journal of Endocrinology

(2017) 176, 657-667
() 2017 European Society of Endocrinology Printed in Great Britain biologically active IGFs to the tissue compartments is, at least in part, regulated by six different IGF-binding proteins (IGFBPs), designated as IGFBP-1 to IGFBP-6 that bind IGFs with high affinities. Normally, IGFBP-3 is the 
most abundant IGFBP in the circulation. Another member of the IGF system is the acid-labile subunit (ALS). ALS is an $85 \mathrm{kDa}$ glycoprotein that forms a relatively large ternary complex, $150 \mathrm{kDa}$, with IGFs and IGFBP-3 (or IGFBP-5) in the circulation and has a major role in its stabilization ( 1 , $2,3,4)$. ALS has no affinity for free IGFs and only binds to binary complexes of IGFs/IGFBP-3 or -5 (3). Under normal circumstances, most of the IGFs are sequestered in these ternary complexes that cannot easily pass the capillary membranes. As a consequence, the half-life of IGFs in the circulation is extended to more than $12 \mathrm{~h}$. In contrast, unbound IGFs and binary IGF-IGFBP complexes are cleared much more rapidly from the circulation, i.e. with half-lives of only $\sim 12$ and $\sim 25$ min respectively (1, $4,5)$. ALS is encoded by IGFALS, located on chromosome $16 \mathrm{p} 13.3$, and is secreted by the liver (2).

Acid-labile subunit deficiency (ACLSD) (OMIM \#615961; \#I.B.4d in the International Classification of Pediatric Endocrine Diagnoses (www.icped.org)), caused by homozygous or compound heterozygous mutations in IGFALS, leads to the failure of ternary complex formation and increased clearance of IGF-I, IGF-II and IGFBP-3 from the circulation (4). IGFALS consists of only 2 exons, with exon 2 encoding the mature ALS protein. Until November 2016, nineteen unique inactivating mutations in IGFALS have been described in 25 patients (all in exon 2) $(4,6,7,8,9)$.

ACLSD is characterized by moderate short stature, low serum levels of IGF-1 and ALS and extremely low levels of IGFBP-3. In contrast, normal basal and stimulated growth hormone (GH) concentrations are found (4). GH treatment trials in ACLSD showed a poor response in terms of growth and serum IGF-1 and IGFBP-3 levels $(2,10,11)$.

In our previous study on a Kurdish family, three siblings with an inactivating homozygous IGFALS mutation showed head circumferences (HCs) that were lower than those of heterozygous and wild-type (WT) relatives (12). A recent case report also reported microcephaly in a 14-year-old girl (8), and in 4 other cases, average HC was -2.2 SDS (range: 4.6-0.1) (9). Anecdotal reports have suggested that the average birth size in cases with ACLSD may be decreased $(3,6,9,13,14,15,16)$, but studies on large families with sufficient heterozygous and WT controls are lacking. In approximately 50\% of males carrying homozygous IGFALS mutations, delayed puberty has been noted $(2,3,4,6,7,10,14,17)$ and variable data on insulin insensitivity and reduced bone mineral density (BMD) have been reported $(2,3,4,6,9$, $10,11,12,14,18)$. The effects on body mass index (BMI) and serum concentrations of IGF-II and IGFBP-2 have not been documented.

In a Kurdish family living in the Netherlands, we showed that heterozygous carriers of an IGFALS mutation are approximately 1 s.D. shorter than non-carriers (12), and this finding was confirmed in an international survey and other reports $(19,20,21)$. However, because of the limited number of affected individuals within each family included in these studies, the statistical validity of the effect of partial ACLSD on the various clinical and laboratory parameters is still weak. Still, the available data indicate that two alleles of IGFALS are required for normal ALS levels, IGF-1 action and growth. We therefore propose that heterozygosity for an inactivating IGFALS mutation could be considered as a medical condition and can be labeled as partial ACLSD.

The present uncertainties regarding the clinical presentation of patients carrying IGFALS mutations, including the effect of complete and partial ACLSD on intrauterine growth, HC, BMI, serum IGF-II and IGFBP-2 levels and BMD, require additional documentation. Here, we report extensive clinical, laboratory and radiological features of a large group of homozygous and heterozygous carriers of three novel IGFALS mutations in reportedly five unrelated Turkish families.

\section{Subjects and methods}

\section{Subjects}

A total of 6 index cases from five consanguineous Turkish families (Fig. 1, panels A, B, C, D and E) were presented to pediatric endocrine clinics in Gaziantep $(n=5)$ and Diyarbakir $(n=1)$ because of short stature. Their medical history was unremarkable, and there were no dysmorphic features found on physical examination. Clinical and laboratory data are shown in Table 1 and further details are presented below. In all cases, the serum levels of IGF-I and ALS were reduced, associated with extremely low IGFBP-3 levels. Along with the pattern of inheritance these findings suggested ACLSD. After confirming the diagnosis by genetic testing, all available family members were invited for growth measurements, venipuncture (for genetic and biochemical testing) and assessment of BMD.

\section{Family $A$}

The index cases were two male cousins (A.III.5 and A.III.14) who were seen at the same visit for short stature (both -3.7 SDS), 1.5-1.6 s.D. shorter than target height (TH). In both 
A
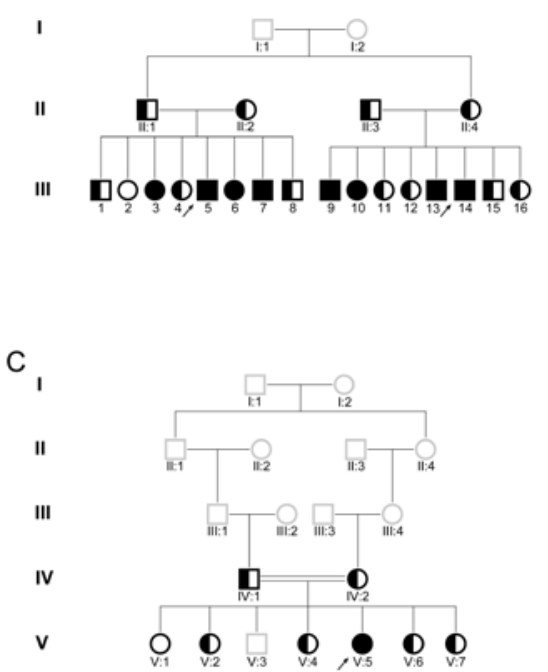

E

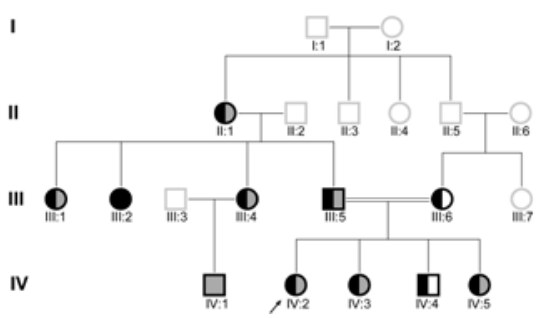

B

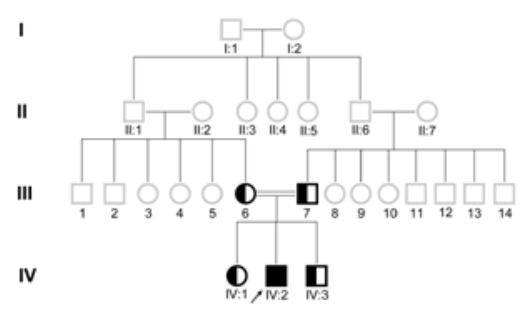

D

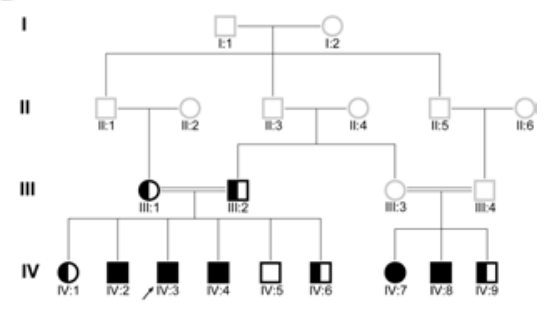

\section{Figure 1}

Pedigrees of families A, B, C, D and E and panels $A, B, C, D$ and $E$ prepared with PedigreeXP (PC PAL, Paris, France). In families A-D, heterozygous and homozygous carriers are indicated with half or completely filled squares and circles. In family E, the black color indicates the Asn84Ser mutation and the dark-gray color the Asp488Asn mutation. Light-gray symbols indicate family members who could not be investigated. cases, serum GH in a random sample was considered too high for explaining the very low serum IGF-I (serum GH levels of 3.75 and $11.9 \mathrm{ng} / \mathrm{mL}$ respectively). Molecular genetics analysis for IGFALS showed a homozygous mutation in exon 2 (c.1462G $>$ A and p.Asp488Asn), which was previously identified in heterozygous state in a South Asian population with an allelic frequency of 0.001 (EXAC - transcript ENST00000215539.3).

\section{Family $B$}

The index case (B.IV.2) was a 9.4-year-old boy with a height of -2.0 SDS, 0.8 s.D. shorter than target height. The peak GH level in a clonidine stimulation test was $26.4 \mathrm{ng} / \mathrm{mL}$. IGFALS sequence analysis showed an identical (c.1462G > A and p.Asp488Asn) mutation, as detected in family A.

\section{Family C}

The index case (C.V.5) was a prepubertal 13.5-year-old girl with a height of -3.6 SDS, 2.8 s.D. shorter than TH. The GH response to a clonidine test was $8.2 \mathrm{ng} / \mathrm{mL}$, and there was no response to an IGF generation test (data not shown).
Molecular genetic analysis showed a novel homozygous IGFALS mutation in exon 2 (c.251A > G and p.Asn84Ser).

\section{Family $D$}

The index case (D.IV.3) was an 11.4-year-old boy with a height of -2.3 SDS, 1.3 s.D. shorter than TH. An L-dopa stimulation test showed a normal peak GH level $(10.3 \mathrm{ng} / \mathrm{mL})$, and there was no response to an IGF generation test (data not shown). Genetic analysis showed a novel homozygous c.1477del and p.Arg493Alafs*176 mutation in exon 2.

\section{Family $E$}

The index case (IV.2) was a prepubertal 11.8-year-old girl with a height of -3.7 SDS, 2.3 s.D. shorter than TH. A clonidine stimulation test revealed a peak $\mathrm{GH}$ level of $8.6 \mathrm{ng} / \mathrm{mL}$. In an IGF generation test, there was a small response of serum IGF-I (74.1-95.2 $\mathrm{ng} / \mathrm{mL}$; reference range 75-440), but no response of serum IGFBP-3 (0.87-0.74 mg/L, reference range 2.7-8.9). Genetic analysis showed a compound heterozygous (c.251A $>\mathrm{G}$, Asn84Ser/c.1462G > A, p.Asp488Asn) mutation in exon 2 of IGFALS. 
Table 1 Clinical features of the index cases of 5 families carrying IGFALS mutations.

\begin{tabular}{|c|c|c|c|c|c|c|}
\hline Index case & A.III.5 & A.III.14 & B.IV.2 & C.V.5 & D.IV.3 & E.IV.2 \\
\hline Mutation & D488N & D488N & D488N & N84S & R493fs & N84S/D488N \\
\hline Sex & $\mathrm{M}$ & $\mathrm{M}$ & $\mathrm{M}$ & $\mathrm{F}$ & $\mathrm{M}$ & $F$ \\
\hline Age (years) & 8.0 & 11.5 & 9.4 & 13.5 & 11.4 & 11.8 \\
\hline Birth weight $(\mathrm{kg})$ & 3.0 & & 2.5 & 2.0 & & 2.5 \\
\hline Birth weight SDS & -1.3 & & -2.6 & -3.8 & & -2.4 \\
\hline Height $(\mathrm{cm})$ & 107.2 & 122.1 & 123.4 & 138.3 & 130.5 & 129 \\
\hline Height SDS & -3.7 & -3.7 & -2.0 & -3.6 & -2.3 & -3.7 \\
\hline BA/CA (years) & $5.0 / 7.4$ & $10.0 / 10.4$ & $6.0 / 9.0$ & $12.0 / 13.5$ & $9.0 / 11.4$ & $12 / 11.8$ \\
\hline Maternal Ht (cm) & 145.5 & 157 & 161.1 & 158.3 & 159.5 & 159 \\
\hline Maternal Ht SDS & -3.0 & -1.0 & -0.3 & -0.8 & -0.5 & -0.7 \\
\hline Paternal Ht $(\mathrm{cm})$ & 166 & 156.5 & 163.2 & 171.5 & 166.7 & 163 \\
\hline Paternal Ht SDS & -1.7 & -3.2 & -2.1 & -0.8 & -1.5 & -2.1 \\
\hline $\mathrm{TH}(\mathrm{cm})$ & 162.3 & 163.2 & 168.6 & 158.4 & 169.6 & 154.5 \\
\hline TH SDS & -2.2 & -2.1 & -1.2 & -0.8 & -1.0 & -1.4 \\
\hline Ht SDS-TH SDS & -1.5 & -1.6 & -0.8 & -2.8 & -1.3 & -2.3 \\
\hline Head circ SDS & -2.9 & -2.8 & -2.0 & -2.1 & -2.2 & -1.9 \\
\hline BMI SDS & -0.3 & -0.5 & -1.2 & -1.6 & -1.6 & -0.1 \\
\hline IGF-I (nmol/L) & 2.2 & 4.7 & 4.8 & 8.3 & 4.2 & 8 \\
\hline IGF-I SDS & -4.5 & -3.6 & -3.3 & -3.2 & -3.8 & -3.0 \\
\hline IGFBP-3 (nmol/L) & 10 & 9 & 7.3 & 8 & 9.3 & 13.3 \\
\hline IGFBP-3 SDS & -9.1 & -10.2 & -11.2 & -8.1 & -10.0 & -6.5 \\
\hline ALS (mU/mL) & $<225$ & $<225$ & $<225$ & $<225$ & $<225$ & $<225$ \\
\hline ALS SDS & $<-2.9$ & $<-3.3$ & $<-3.1$ & $<-5.5$ & $<-3.3$ & $<-5.4$ \\
\hline
\end{tabular}

ALS, acid labile subunit; BA, bone age; BMI, body mass index; CA, chronological age; circ, circumference; F, female; Ht, height; IGF-I, insulin-like growth factor I; IGFBP-3, insulin-like growth factor binding protein 3; M, male; SDS, standard deviation score; TH, target height.

\section{Methods}

We obtained approval for the study from the Ethics Committee of Gaziantep University (application 2016/139) and informed consent for genetic analysis and further studies from all family members and/or their legal guardians.

Height and weight were measured using standard anthropometric devices, and standard deviation scores (SDS) for height were calculated according to growth charts for the Turkish population (22). TH was calculated using the equation TH (centimeters) $=$ (father's height $(\mathrm{cm})+$ mother's height $(\mathrm{cm})) / 2-6.5 \mathrm{~cm}$ (girls) or $+6.5 \mathrm{~cm}$ (boys) (23), and TH SDS was calculated using reference data for the Turkish population (22).

To evaluate the difference in height SDS between ACLSD and partial ACLSD, we took three approaches, the first two of which accounted for inter-family differences, to prevent confounding. First, for ACLSD patients in families A-D, we calculated the difference between their respective actual height SDS and TH SDS values. Secondly, for all ACLSD patients, we calculated the weighted average of the difference between height SDS of cases with p.ACLSD and partial ACLSD in the five families. Thirdly, we compared mean height SDS between all cases with ACLSD and partial ACLSD.
In the absence of Turkish reference data, HC SDS was calculated based on 1997 Dutch reference (24). Birth weight SDS was calculated based on the Swedish references (25), which proved similar to those of Turkish babies living in the Netherlands (26). In all cases, gestational age was reported as 'term', which we interpreted as 40 weeks. For children and adolescents, pubertal stage was assessed according to Tanner. Bone age was assessed using the Greulich and Pyle method (27). For all adolescent and adult females, the age at menarche was recorded. From adult males, we collected data on the age at onset of accelerated growth and shaving.

IGF-I in serum was determined by an immunometric technique on an IMMULITE 1000 Analyzer (Siemens Medical Solutions Diagnostics). Serum levels of IGFBP-3 and IGFBP-2 were determined by specific in-house RIAs. Serum total ALS levels were determined using the ELISA kit obtained from Mediagnost (Reutlingen, Germany). All plasma samples were diluted 150-fold before measurement in sample buffer, as recommended by the manufacturer. As the lowest standard in the ELISA was $1.5 \mathrm{mU} / \mathrm{mL}$, measurements of less than $225 \mathrm{mUALS} / \mathrm{mL}$ plasma may become inaccurate, although the duplicates showed less than $10 \%$ differences, which is in fact a quality requirement in the lab. We therefore decided to 
report plasma levels $<225 \mathrm{mU} / \mathrm{mL}$ as below the practical detection limit and calculated the SDS accordingly. Assay characteristics and smoothed normative ranges values, as constructed by the LMS method, of the various laboratory parameters mentioned previously have been published elsewhere $(28,29,30)$.

Ternary complex formation was investigated by size-exclusion chromatography as described previously $(12,31)$. In the index cases in families C, D and E, IGF generation tests were performed $(33 \mu \mathrm{g} / \mathrm{kg} / \mathrm{day}$ for 3 days, venous samples taken before the first injection and on day 4 in index cases in family $\mathrm{C}$ and $\mathrm{E}$ and $50 \mu \mathrm{g} / \mathrm{kg} /$ day for 7 days, venous samples taken before the first injection and on day 8 in the index case in family D).

Genomic DNA was isolated from peripheral blood samples using PUREGENE nucleic acid purification chemistry on the AUTOPURE LS 98 Instrument (Qiagen). Sequence analysis of IGFALS (NC_000016.9/NM_004970.2) was performed as described previously (12).

BMD was measured by Dual-energy X-ray (Horizon DXA system, Hologic), and z-scores were calculated according to NHANES scores (32). To eliminate the impact of short stature on BMD z-score, sex and age-specific height-adjusted BMD (Ha-BMD), z-scores were calculated (33). As for subjects aged $>20$ years, no appropriate age references are available, we compared their Ha-BMD with 20-year-old adults.

\section{Statistical analysis}

Statistical analysis was carried out using IBM SPSS Statistics for Windows (version 22.0. Armonk, NY: IBM Corp. Released 2013). Data were expressed as mean \pm s.D. (range). The Shapiro-Wilk test was used to test for a normal distribution of the data. Means were compared using Student's $t$ test for normally distributed data, whereas for non-normally distributed data and for the groups with small number of cases, medians were compared using non-parametric Mann-Whitney $U$ test. The SpearmanRank test was performed for correlations. A $P$ value $<0.05$ was considered statistically significant.

\section{Results}

\section{Clinical, biochemical and radiological data per family}

Clinical, biochemical and radiological data of all available individual members of the five families are shown in
Supplementary Tables $1,2,3,4$ and 5 (see section on supplementary data given at the end of this article).

For two cases, medical disorders were reported. Case A.III.13 (homozygous for p.Asp488Asn) was born with anal atresia, had unilateral nephrectomy due to atrophic kidney at the age of 7 years and also had a history of frequent diarrhea and clavicle fracture after a minor trauma. Case E.IV.4 (heterozygous for p.Asn84Ser) reported gastroesophageal reflux disease complicated by bronchiectasis.

For families A and D (Supplementary Tables 1 and 4), the numbers of cases with ACLSD and partial ACLSD were sufficient to produce statistics with regard to the clinical, biochemical and radiological data. In family A, homozygous IGFALS mutations were encountered in 8 cases $(6<18$ years), heterozygotes in 11 family members $(7<18$ years) and one non-carrier (WT). In family D, 5 homozygous and 5 heterozygous carriers were found, and one WT. In both families, differences between homozygous and heterozygous carriers were statistically significant for SDS values of height, HC, IGF-I, IGFBP-3, ALS and IGF-II. Ternary complex formation in sera of the index cases was markedly diminished, whereas heterozygous

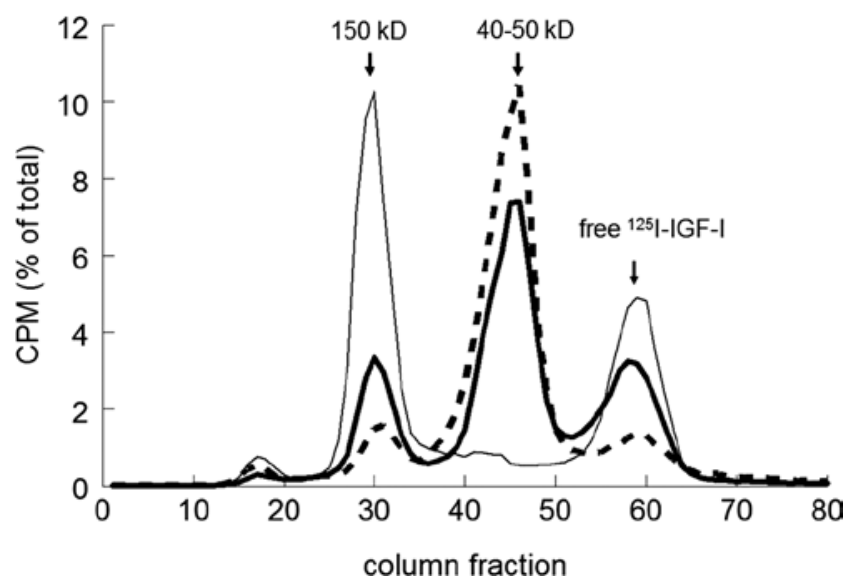

Figure 2

Distribution of radioactivity among the various MW size classes after S200 size-exclusion chromatography of pooled normal serum (thin black line), index patient III.14, homozygous for the c.1462G > A, p.Asp488Asn mutation in ALS (family A) (dashed line) and a heterozygous family member (II.2) (thick solid black line). Prior to column chromatography, $250 \mu \mathrm{L}$ of each serum was incubated with $100 \mu \mathrm{L}$ of $\sim 100000 \mathrm{cpm}$. ${ }^{125} \mathrm{I}$-IGF-I for $18-20 \mathrm{~h}$ at $4^{\circ} \mathrm{C}$. The ${ }^{125} \mathrm{I}$ content of each successive $1.2 \mathrm{~mL}$ fraction was counted in a $\gamma$-counter and expressed as percentage (II.2) radioactivity recovered from the column. 
family members showed an intermediate pattern when compared to the normal situation. This is illustrated in Fig. 2 for one of the index cases of family A (III.14) and a carrier (II.2) of the IGFALS mutation. In these two families, the average height differences between ACLSD and partial ACLSD were 1.6 and 1.1 S.D.; the respective differences in HC were 1.2 and 0.6 S.D.

In families B and C (Supplementary Tables 2 and 3), the data of only one homozygous case could be compared with 4 and 6 heterozygotes respectively. Height SDS of the index cases vs the mean of the heterozygotes in these families were -2.0 vs -0.9 SDS (family B) and -3.6 vs -1.0 (family C), thus, differences of 1.1 and 2.6 s.D. respectively. In family C, HC SDS of the index case was 2.8 S.D. lower compared with the mean of the six heterozygous carriers ( -2.1 vs +0.7 SDS).

In family $\mathrm{E}$ (Supplementary Table 5), father was compound heterozygous (p.Asn84Ser/p.Asp488Asn) and mother was heterozygous for the p.Asn84Ser mutation. One case, a cousin of the index patient, was homozygous for p.Asp488Asn mutation (IV.1), another case (III.2) was homozygous for the p.Asn84Ser mutation and seven were compound heterozygotes. There were only two heterozygous carriers. Mean height of the two heterozygotes ( -1.9 SDS) was 0.3 s.D. above the combined homozygous and compound heterozygous cases ( -2.2 SDS). Ternary complex formation in sera from the index patients and heterozygous family members was affected in a similar way as for family A (data not shown).

\section{Combined analysis}

Tables 2 and 3 show the mean \pm s.D. (range) of the clinical, biochemical and radiological data of 24 cases with ACLSD, 26 with partial ACLSD and 3 non-carriers (WT) in the five families combined. A graphical representation is shown in Fig. 3. In comparison with partial ACLSD, cases with ACLSD were shorter and leaner, had a smaller head circumference and lower SDS values of serum IGF-I, IGF-II, IGFBP-2, IGFBP-3 and ALS. The Spearman correlation analysis revealed that serum IGF-I SDS correlated stronger with HC SDS $(r=0.653, P<0.001)$ than IGF-II $(r=0.524 ; P<0.001)$. Serum IGFBP-2 levels also tended to be lower for ACLSD patients, but the difference did not reach statistical significance $(P=0.06)$. Five out of 7 cases with ACLSD had a birth weight $<-2.0$ SDS, vs none of the partial ACLSD cases $(n=3)$, but the difference between the means did not reach statistical significance $(P=0.067)$.

Table 2 Clinical features of 5 families carrying IGFALS mutations.

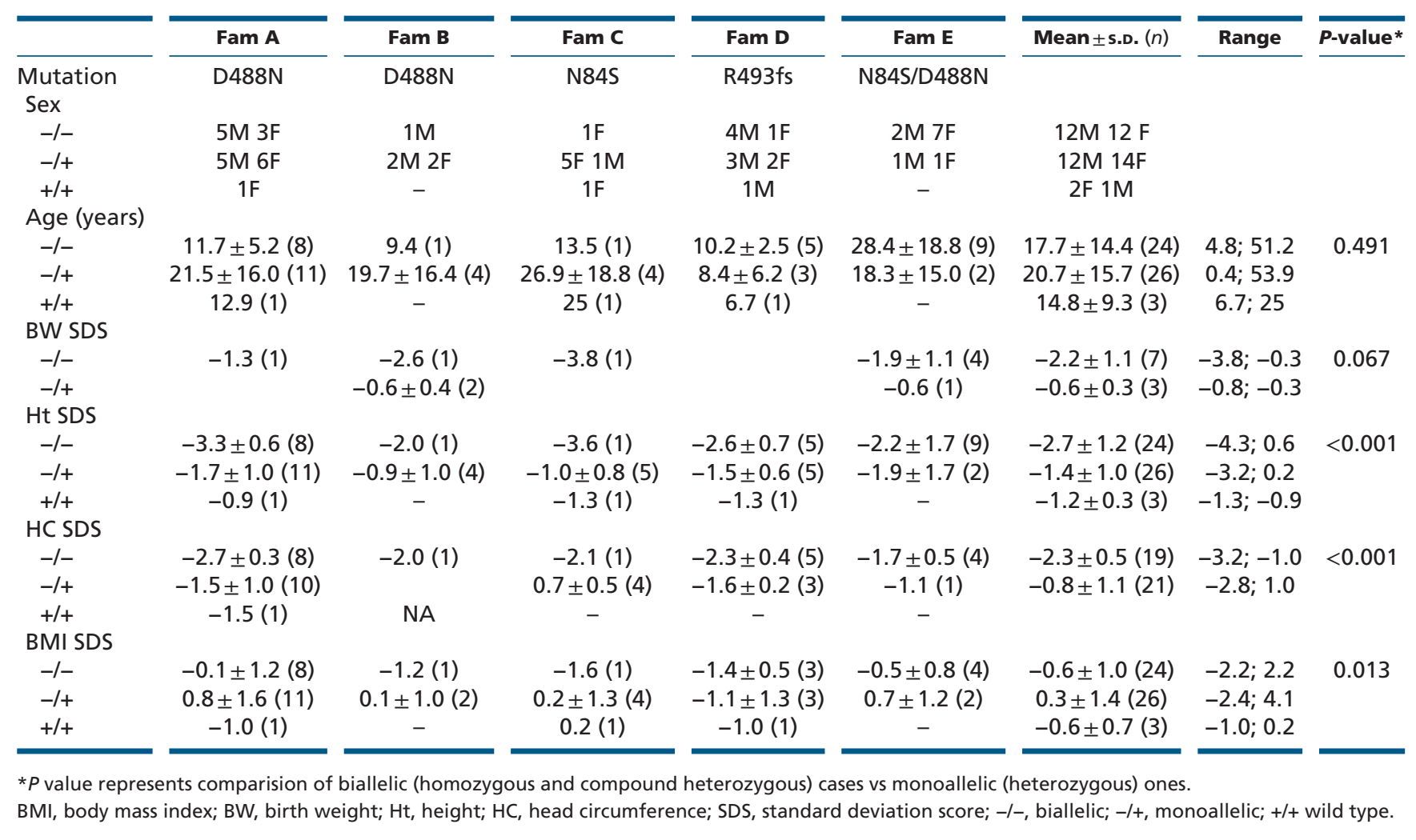


Table 3 Biochemical features and height adjusted BMD z score of 5 families carrying IGFALS mutations.

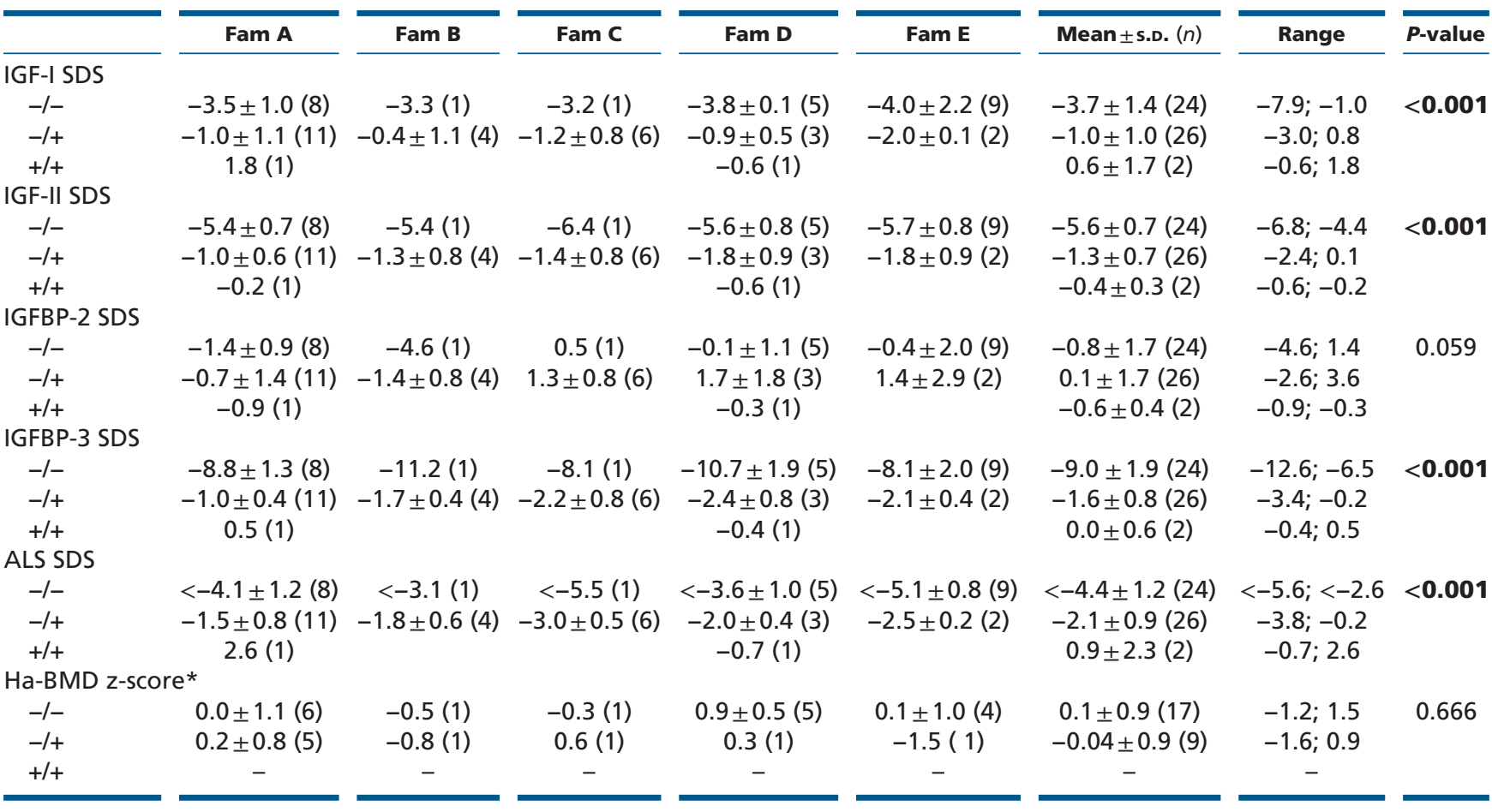

$P$ value represents comparision of biallelic (homozygous and compound heterozygous) cases vs monoallelic (heterozygous) ones. *Only calculated for children and adolescents.

ALS, acid labile subunit; Ha-BMD, bone mineral density z-score adjusted for height; IGF-I, insulin-like growth factor I; IGF-II, insulin-like growth factor II; IGFBP-2, insulin-like growth factor binding protein 2; IGFBP-3, insulin-like growth factor binding protein 3; SDS, standard deviation score.

Ha-BMD in adults could not be compared between groups because of the uneven distribution (no homozygous mutation carriers in families $\mathrm{A}, \mathrm{B}$ and $\mathrm{C}$, and only one heterozygous carrier in family $\mathrm{E}$ ). If for adult cases reference data of 20-year-old adults were used, all

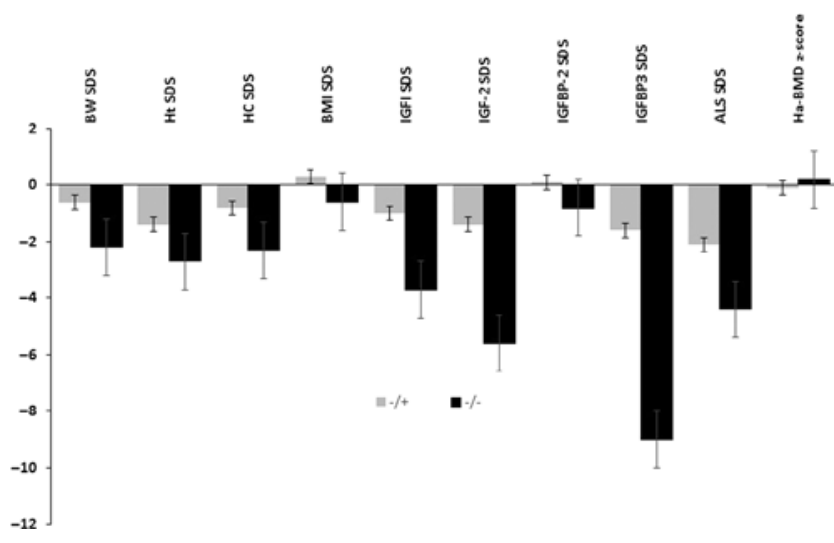

Figure 3

Graphical representation of mean \pm S.D. of SDS values of clinical and laboratory characteristics of cases with ACLSD (black bars) and partial ACLSD (gray bars). Ha-BMD z-score is only shown for cases $\leq 20$ years.
Ha-BMD data were normal and not different between groups (data not shown). For children and adolescents, Ha-BMD SDS was $0.1 \pm 0.9$ and $-0.0 \pm 0.9$ in ACLSD and partial ACLSD respectively $(P=0.666)$.

\section{Height difference between ACLSD and partial ACLSD}

For all children with ACLSD in families A-D, we calculated the difference between height SDS and TH SDS, to assess the effect of homozygosity vs heterozygosity for IGFALS mutations. This difference in children with ACLSD $(n=15)$ was $-1.2 \pm 0.6$ s.D. (95\% confidence interval (CI) -1.6 to -0.9 ), whereas children with partial ACLSD $(n=17)$ were predicted to become $0.3 \pm 0.9$ S.D. $(95 \% \mathrm{CI}$ : -0.2 to +0.8$)$ taller than their parents $(P<0.001)$ (Fig. 4$)$. Thus, using this approach, the effect of two defective alleles vs one could therefore be estimated as $~ 1.5$ s.D. The weighted average of the difference between height SDS of cases with ACLSD and partial ACLSD in the five families was 1.3 s.D. When all cases with ACLSD and partial ACLSD were compared, the difference was also 1.3 s.D. (Table 2).

Due to the known increased occurrence of delayed puberty, we tested whether height SDS has a positive 


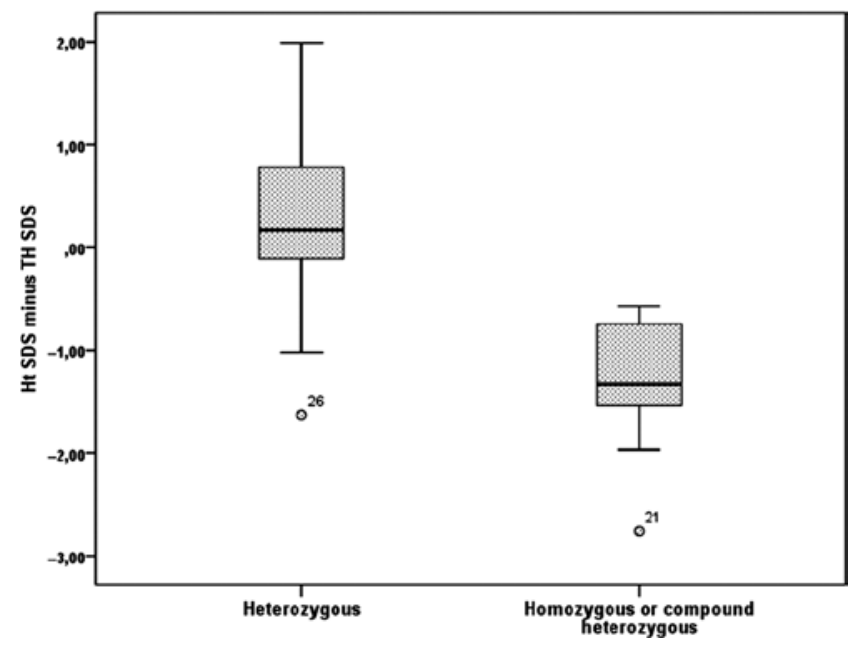

\section{Figure 4}

Boxplots of difference between height SDS and target height SDS for children with ACLSD and partial ACLSD.

correlation with age in cases with both groups. Regression analysis revealed no statistically significant correlation between age and height SDS in both ACLSD $(r=-0.116$; $P=0.589)$ and partial ACLSD $(r=-0.136 ; P=0.507)$.

\section{Discussion}

Fifty subjects belonging to five families carry one or two out of three IGFALS mutations in exon 2, which so far have not been associated with ACLSD. It is important that such mutations are registered in the literature and an international database (34) for future genetic diagnostic purposes. The c.1462G >A, p.Asp488Asn mutation (families A, B and E), previously only identified in heterozygous state in a South Asian population, introduces a potentially new $\mathrm{N}$-glycosylation site (i.e. Asn-X-Thr/Ser), which will probably result in misfolding of the protein leading to its relatively rapid intracellular degradation (35). Several protein prediction algorithms conclude that this mutation, which is located in a highly conserved amino acid, is pathogenic (SIFT: deleterious (score 0; median: 3.74); PolyPhen: probably damaging (score of 1.000); MutationTaster: disease causing ( $P$ value: 0.787)). The p.Asn84Ser mutation (families $C$ and E) replaces an asparagine by a serine. This amino acid is also highly conserved, and the mutation is predicted to be pathogenic by the algorithms (SIFT: Deleterious (score: 0, median: 3.64); PolyPhen: probably damaging (score of 1.000); MutationTaster: disease causing ( $P$ value: 1$)$ ). The c.1477del, p.Arg493Alafs*176 mutation is probably subject to nonsense-mediated decay and not expressed at all. If expressed, the mutant ALS protein would loose two of its consensus motifs for leucine-rich repeats (LRRs), which would be replaced by 176 new amino acids. These LRRs are considered to be involved in the interaction between ALS and IGFBP-3 or-5 $(35,36,37)$. Additional functional studies are needed to confirm these theoretical considerations, but the data on ternary complex formation, extremely low serum ALS and cosegregation of the mutations with the clinical and laboratory phenotype in these families make it extremely likely that these mutations are pathogenic. We speculate that the occurrence of the same mutations in more than one reportedly unrelated families is most likely caused by a founder effect because they all lived in the same region of Turkey.

Our findings confirm previous reports that the main clinical feature of children with ACLSD is moderate short stature (mean height -2.7 SDS, i.e. 1.3-1.5 s.D. shorter than heterozygous relatives); only 4 of 24 cases had a height above the cutoff of -2 SDS. We also confirm that a combination of a low serum IGF-I level with an extremely low IGFBP-3 concentration, low serum ALS and reduced ternary complex formation represent the main biochemical characteristics of ACLSD. We further show that heterozygous carriers are relatively short and that height-adjusted BMD is within the normal range in both groups. Novel findings include that most cases with ACLSD are born SGA, have a HC below -2 SDS (mean head circumference -2.3 SDS, i.e. 1.5 s.D. smaller than that in partial ACLSD) and have a low serum IGF-II, whereas serum IGFBP-2 levels are in the low-normal range. Our observation that BMI SDS in ACLSD is slightly lower (but reaching statistical significance) than that in partial ACLSD is novel, but not relevant from a clinical point of view.

Delayed puberty, as previously reported in 50\% of males with ACLSD, is considered one of the most frequent clinical characteristics of this condition. As most of our cases with ACLSD were young, and information about pubertal onset of family members was of dubious accuracy, our data do not allow for any conclusion about pubertal timing. Assuming that the adults in the five families also had experienced a delayed puberty, we speculated that the effect on adult height might be less severe than that on height SDS during childhood. However, we could not confirm this in our study.

The difference in height SDS between ACLSD and partial ACLSD in our study (1.3-1.5 s.D.) is similar to what we previously reported in one family (12) and to results published by the International ALS Consortium (19). The 
relatively low mean height SDS of partial ACLSD in our study is also consistent with previous reports indicating that heterozygosity for an IGFALS mutation leads to an average loss of approximately 1 S.D. $(12,19,20)$, in line with a gene dosage effect (i.e. the expression of both IGFALS alleles is necessary for normal growth). However, the number of non-carriers in the five families in this study was too small to document this statistically.

In this study, we demonstrate that $\mathrm{HC}$ and birth size are significantly smaller in patients with ACLSD than in partial ACLSD, confirming previous anecdotal observations for head circumference $(8,9,12)$ and birth weight $(3,6$, $9,12,13,14,15,16)$, although both in our study and the previous review (3) birth weight was only known for 7-8 cases, with unknown accuracy of the reported gestational age (in all except one case reported as 'term'). Previous studies have shown that IGF-I is necessary for normal fetal growth and development, and particularly for brain development, as illustrated by the severe microcephaly and low birth size of patients with IGF1 or IGF1R defects $(38,39,40,41,42,43,44)$. The effect of IGF-II deficiency on birth size and HC appears to be less than that of IGF-I (45), which is in line with our finding that the correlation between HC SDS with serum IGF-I was stronger than that with serum IGF-II. We speculate that the exposure of the developing fetus, including its brain, to IGFs is decreased in patients with ACLSD, resulting in a relatively low birth weight and $\mathrm{HC}$, but apparently this has no detrimental effect on intellectual development. This speculation is also supported by a recent study showing that umbilical cord ALS levels are positively correlated with birth weight, head circumference and placental weight (46).

Several reports suggested that ACLSD may cause low $\operatorname{BMD}(3,6,12,18)$, but it was found normal in other reports $(9,11,14)$. The present results show that Ha-BMD in children and teenagers with ACLSD is normal and not different from partial ACLSD. Our observations in adults suggest that the same is true for that age range, although the unequal distribution of heterozygous and homozygous mutations in these families did not allow for a proper comparison. In addition, there was no history of bone pain or fracture, except for one homozygous patient (A.III.13) with serious coexisting medical disorders. Our findings are consistent with the most recent interpretation of data on bone biology i.e. ACLSD creates a phenotype of slender bones of normal density (9), similar to that observed in Als-deficient mice (47). Although there is no doubt that for a proper interpretation of BMD assessed by DXA an adjustment for body height is necessary (33, $48,49)$, there is no consensus about the most appropriate method. We compared apparent BMD (representing volumetric BMD instead of areal BMD) (50) and heightadjusted BMD (33) and chose the latter, because this method involves 4 comprehensive steps taking into account the bone mineral content, sex, age, race and height of the subjects in the calculation of BMD. Besides, it has been developed and tested in a large number of healthy children and adolescents with more than 10000 DXA measurements.

With respect to biochemical findings, for the clinician the combination of a markedly low IGFBP-3, low IGF-I and a normal GH secretion in a moderately short child makes the diagnosis of ACLSD sufficiently likely to perform genetic testing. In the present paper, we show that serum IGF-II SDS is even lower than IGF-I SDS and that serum IGFBP-2 is usually in the low-normal range, but tends to be lower in ACLSD than that in partial ACLSD $(P=0.059)$. The ALS ELISA revealed some detectable ALS immunoreactivity in sera from all patients with ACLSD, albeit clearly below the lowest standard in the assay. It is unclear whether the (very) small amount of ALS detected (which may also represent fragments, cross reactive material, or a matrix effect) is of any biological importance. On the other hand, the column gel filtration experiments showed the presence of a (very) small amount of ternary complex in ACLSD patients, as shown in Fig. 2.

In conclusion, our results expand the characteristics of the clinical phenotype of ACLSD by an increased percentage of low birth weight (SGA), low HC (microcephaly) and leanness, and show that besides decreased serum IGFBP-3, IGF-I and ALS, also IGF-II is decreased, whereas BMD appears normal for height.

\section{Supplementary data}

This is linked to the online version of the paper at http://dx.doi.org/10.1530/ EJE-16-0999.

\section{Declaration of interest}

The authors declare that there is no conflict of interest that could be perceived as prejudicing the impartiality of this study.

\section{Funding}

This research did not receive any specific grant from any funding agency in the public, commercial or not-for-profit sector.

\section{Acknowledgements}

The authors are grateful for the willingness of the patients and their family members to participate in this study; they gratefully acknowledge the help of Jani Soderhal (PC PAL, Paris, France) in preparing the pedigrees and thank Dr Christiaan de Bruin MD, PhD for advice on earlier versions of the manuscript. 
14 Heath KE, Argente J, Barrios V, Pozo J, Diaz-Gonzalez F, MartosMoreno GA, Caimari M, Gracia R \& Campos-Barros A. Primary acid-labile subunit deficiency due to recessive IGFALS mutations results in postnatal growth deficit associated with low circulating insulin growth factor (IGF)-I, IGF binding protein-3 levels, and hyperinsulinemia. Journal of Clinical Endocrinology and Metabolism 200893 1616-1624. (doi:10.1210/jc.2007-2678)

15 Storr HL, Prasad R, Temple IK, Metherell LA, Savage MO \& Walker JM. Heterogeneity of the growth phenotype and birth size in acid-labile subunit (ALS) deficiency. Journal of Endocrinological Investigation 2015 38 407-412. (doi:10.1007/s40618-014-0195-1)

16 Storr HL, Dunkel L, Kowalczyk J, Savage MO \& Metherell LA. Genetic characterisation of a cohort of children clinically labelled as GH or IGF1 insensitive: diagnostic value of serum IGF1 and height at presentation. European Journal of Endocrinology 2015172 151-161. (doi:10.1530/EJE-14-0541)

17 Hwa V, Haeusler G, Pratt KL, Little BM, Frisch H, Koller D \& Rosenfeld RG. Total absence of functional acid labile subunit, resulting in severe insulin-like growth factor deficiency and moderate growth failure. Journal of Clinical Endocrinology and Metabolism 2006 91 1826-1831. (doi:10.1210/jc.2005-2842)

18 Domene HM, Bengolea SV, Jasper HG \& Boisclair YR. Acid-labile subunit deficiency: phenotypic similarities and differences between human and mouse. Journal of Endocrinological Investigation 200528 43-46.

19 Fofanova-Gambetti OV, Hwa V, Wit JM, Domene HM, Argente J, Bang P, Hogler W, Kirsch S, Pihoker C, Chiu HK et al. Impact of heterozygosity for acid-labile subunit (IGFALS) gene mutations on stature: results from the international acid-labile subunit consortium. Journal of Clinical Endocrinology and Metabolism 201095 4184-4191. (doi:10.1210/jc.2010-0489)

20 Domene HM, Scaglia PA, Martinez AS, Keselman AC, Karabatas LM, Pipman VR, Bengolea SV, Guida MC, Ropelato MG, Ballerini MG et al. Heterozygous IGFALS gene variants in idiopathic short stature and normal children: impact on height and the IGF system. Hormone Research in Paediatrics 201380 413-423. (doi:10.1159/000355412)

21 Grandone A, Miraglia del Giudice E, Cirillo G, Abbondanza C, Cioffi M, Romano T, Micillo F, Marzuillo P \& Perrone L. Clinical features of a new acid-labile subunit (IGFALS) heterozygous mutation: anthropometric and biochemical characterization and response to growth hormone administration. Hormone Research in Paediatrics 2014 81 67-72. (doi:10.1159/000355017)

22 Neyzi O, Bundak R, Gokcay G, Gunoz H, Furman A, Darendeliler F \& Bas F. Reference values for weight, height, head circumference, and body mass index in turkish children. Journal of Clinical Research in Pediatric Endocrinology 20157 280-293. (doi:10.4274/jcrpe.2183)

23 Tanner JM, Goldstein H \& Whitehouse RH. Standards for children's height at ages 2-9 years allowing for height of parents. Archives of Disease in Childhood 197045 755-762. (doi:10.1136/ adc.45.244.755)

24 Fredriks AM, Van Buuren S, Burgmeijer RJ, Meulmeester JF, Beuker RJ, Brugman E, Roede MJ, Verloove-Vanhorick SP \& Wit JM. Continuing positive secular growth change in The Netherlands 1955-1997. Pediatric Research 200047 316-323. (doi:10.1203/00006450200003000-00006)

25 Niklasson A, Ericson A, Fryer JG, Karlberg J, Larwence C \& Karlberg P. An update of the Swedish reference standards for weight, length and head circumeference at birth for given gestational age (1977-1981). Acta Paediatrica Scandinavica 199180 756-762. (doi:10.1111/j.1651-2227.1991.tb11945.x)

26 Visser GH, Eilers PH, Elferink-Stinkens PM, Merkus HM \& Wit JM. New Dutch reference curves for birthweight by gestational age. Early Human Development 200985 737-744. (doi:10.1016/j. earlhumdev.2009.09.008)

27 Greulich WW \& Pyle SJ. Radiographic Atlas of Skeletal Development of the Hand and Wrist. California, USA: Stanford University Press, 1959. 
28 Rikken B, van Doorn J, Ringeling A, Van den Brande JL, Massa G $\&$ Wit JM. Plasma levels of insulin-like growth factor (IGF)-I, IGF-II and IGF-binding protein-3 in the evaluation of childhood growth hormone deficiency. Hormone Research 199850 166-176. (doi:10.1159/000023268)

29 de Kort SW, van Doorn J, van de Sande AG, Leunissen RW \& HokkenKoelega AC. Serum insulin-like growth factor-binding protein-2 levels and metabolic and cardiovascular risk factors in young adults and children born small for gestational age. Journal of Clinical Endocrinology and Metabolism 201095 864-871. (doi:10.1210/jc.20091508)

30 Bakker NE, van Doorn J, Renes JS, Donker GH \& Hokken-Koelega AC. IGF-1 levels, complex formation, and igf bioactivity in growth hormone-treated children with prader-willi syndrome. Journal of Clinical Endocrinology and Metabolism 2015100 3041-3049. (doi:10.1210/jc.2015-1410)

31 Renes JS, van Doorn J \& Hokken-Koelega AC. Ternary complex formation and IGFBP-3 proteolytic activity during childhood: agedependent changes. Journal of Clinical Endocrinology and Metabolism 201499 E1988-E1996. (doi:10.1210/jc.2013-3814)

32 Kelly TL, Wilson KE \& Heymsfield SB. Dual energy X-Ray absorptiometry body composition reference values from NHANES. PLOS ONE 20094 e7038. (doi:10.1371/journal.pone.0007038)

33 Zemel BS, Kalkwarf HJ, Gilsanz V, Lappe JM, Oberfield S, Shepherd JA, Frederick MM, Huang X, Lu M, Mahboubi S et al. Revised reference curves for bone mineral content and areal bone mineral density according to age and sex for black and non-black children: results of the bone mineral density in childhood study. Journal of Clinical Endocrinology and Metabolism 201196 3160-3169. (doi:10.1210/ jc.2011-1111)

34 Rosenfeld RG \& von Stein T. A database and website for molecular defects of the GH-IGF axis: www.growthgenetics.com. Hormone Research in Paediatrics 201380 443-448. (doi:10.1159/000355543)

35 Firth SM, Yan X \& Baxter RC. D440N mutation in the acid-labile subunit of insulin-like growth factor complexes inhibits secretion and complex formation. Molecular Endocrinology 201125 307-314. (doi:10.1210/me.2010-0295)

36 Janosi JB, Ramsland PA, Mott MR, Firth SM, Baxter RC \& Delhanty PJ. The acid-labile subunit of the serum insulin-like growth factorbinding protein complexes. Structural determination by molecular modeling and electron microscopy. Journal of Biological Chemistry 1999274 23328-23332. (doi:10.1074/jbc.274.33.23328)

37 David A, Kelley LA \& Sternberg MJ. A new structural model of the acid-labile subunit: pathogenetic mechanisms of short stature-causing mutations. Journal of Molecular Endocrinology 201249 213-220. (doi:10.1530/JME-12-0086)

38 Woods KA, Camacho-Hubner C, Savage MO \& Clark AJ. Intrauterine growth retardation and postnatal growth failure associated with deletion of the insulin-like growth factor I gene. New England Journal of Medicine 1996335 1363-1367. (doi:10.1056/ NEJM199610313351805)
39 Abuzzahab MJ, Schneider A, Goddard A, Grigorescu F, Lautier C, Keller E, Kiess W, Klammt J, Kratzsch J, Osgood D et al. IGF-I receptor mutations resulting in intrauterine and postnatal growth retardation. New England Journal of Medicine 2003349 2211-2222. (doi:10.1056/ NEJMoa010107)

40 Randhawa R \& Cohen P. The role of the insulin-like growth factor system in prenatal growth. Molecular Genetics and Metabolism 200586 84-90. (doi:10.1016/j.ymgme.2005.07.028)

41 Walenkamp MJ, Karperien M, Pereira AM, Hilhorst-Hofstee Y, van Doorn J, Chen JW, Mohan S, Denley A, Forbes B, van Duyvenvoorde HA et al. Homozygous and heterozygous expression of a novel insulin-like growth factor-I mutation. Journal of Clinical Endocrinology and Metabolism 200590 2855-2864. (doi:10.1210/ jc.2004-1254)

42 Walenkamp MJ, van der Kamp HJ, Pereira AM, Kant SG, van Duyvenvoorde HA, Kruithof MF, Breuning MH, Romijn JA, Karperien M \& Wit JM. A variable degree of intrauterine and postnatal growth retardation in a family with a missense mutation in the insulin-like growth factor I receptor. Journal of Clinical Endocrinology and Metabolism 200691 3062-3070. (doi:10.1210/jc.2005-1597)

43 Klammt J, Kiess W \& Pfaffle R. IGF1R mutations as cause of SGA. Best Practice and Research: Clinical Endocrinology and Metabolism 201125 191-206. (doi:10.1016/j.beem.2010.09.012)

44 Netchine I, Azzi S, Le BY \& Savage MO. IGF1 molecular anomalies demonstrate its critical role in fetal, postnatal growth and brain development. Best Practice and Research: Clinical Endocrinology and Metabolism 201125 181-190. (doi:10.1016/j.beem.2010.08.005)

45 Begemann M, Zirn B, Santen G, Wirthgen E, Soellner L, Buttel HM, Schweizer R, van WW, Binder G \& Eggermann T. Paternally inherited IGF2 mutation and growth restriction. New England Journal of Medicine 2015373 349-356. (doi:10.1056/NEJMoa1415227)

46 Tseng YM, Hwang YS, Lu CL, Lin SJ \& Tsai WH. Association of umbilical cord plasma acid-labile subunit of the insulin-like growth factor ternary complex with anthropometry in term newborns. Pediatrics and Neonatology 201455 139-144. (doi:10.1016/j. pedneo.2013.09.002)

47 Courtland HW, DeMambro V, Maynard J, Sun H, Elis S, Rosen C \& Yakar S. Sex-specific regulation of body size and bone slenderness by the acid labile subunit. Journal of Bone and Mineral Research 201025 2059-2068. (doi:10.1002/jbmr.94)

48 Leonard MB \& Zemel BS. Current concepts in pediatric bone disease. Pediatric Clinics of North America 200249 143-173. (doi:10.1016/ S0031-3955(03)00113-5)

49 Gordon CM, Bachrach LK, Carpenter TO, Crabtree N, El-Hajj Fuleihan G, Kutilek S, Lorenc RS, Tosi LL, Ward KA, Ward LM et al. Dual energy X-ray absorptiometry interpretation and reporting in children and adolescents: the 2007 ISCD Pediatric Official Positions. Journal of Clinical Densitometry 200811 43-58. (doi:10.1016/j.jocd.2007.12.005)

50 Carter DR, Bouxsein ML \& Marcus R. New approaches for interpreting projected bone densitometry data. Journal of Bone and Mineral Research 19927 137-145. (doi:10.1002/jbmr.5650070204)

Received 4 December 2016

Revised version received 13 February 2017

Accepted 1 March 2017 